\title{
A New Flavone $C$-Glycoside from the Style of Zea mays L. with Glycation Inhibitory Activity
}

\author{
Ryuichiro Suzuki, Yoshihito OKada, and Toru OKuYama* \\ Department of Natural Medicine and Phytochemistry, Meiji Pharmaceutical University; 2-522-1 Noshio, Kiyose, Tokyo \\ 204-8588, Japan. Received May 16, 2003; accepted June 26, 2003
}

\begin{abstract}
A new flavone $C$-glycoside, chrysoeriol 6- $C$ - $\beta$-fucopyranoside (1), and a known flavone $C$-glycoside (2) were isolated from the style of Zea mays $\mathrm{L}$. These structures were elucidated on the basis of spectroscopic analysis. Compound 1 exhibited glycation inhibitory activity.
\end{abstract}

Key words Zea mays; chrysoeriol 6- $C$ - $\beta$-fucopyranoside; glycation inhibitory activity

The style of Zea mays L. (Gramineae) is commonly known as "corn silk" and has been used in folk medicine as a decoction for diuretic treatment in Japan and China. In previous research on this material, ${ }^{1)}$ we reported the isolation of a new flavone $C$-glycoside, which contains the rare sugar boivinose. Further investigation of the style of Zea mays led to isolation and characterization of a new flavone $C$-glycoside, chrysoeriol 6-C- $\beta$-fucopyranoside (1), along with a known flavone $C$-glycoside, ax-4"-OH-3'-methoxymaysin (2). ${ }^{2)}$ The structures of 1 and $\mathbf{2}$ were determined by employing two dimensional (2D) NMR techniques including ${ }^{1} \mathrm{H}-{ }^{1} \mathrm{H}$ correlation spectroscopy (COSY), ${ }^{1} \mathrm{H}-{ }^{13} \mathrm{C}$ heteronuclear multiple quantum coherence (HMQC), and ${ }^{1} \mathrm{H}_{-}{ }^{13} \mathrm{C}$ heteronuclear multiple bond coherence (HMBC) experiments.

Isolated compounds were also tested for inhibitory activity on glycation. The aldehyde group of reducing sugar and amino residue in protein react and result in the formation of some kinds of aggregate (advanced glycation end products; AGEs) such as $N$ - $\varepsilon$-(carboxymethyl) lysine (CML) and pentosidine. This process is referred to as glycation, and it is known that the formation of these AGEs in the human body through glycation is associated with the inducement of diabetic complications. ${ }^{3)}$

Compound 1, yellow amorphous solid, had the molecular formula $\mathrm{C}_{22} \mathrm{H}_{22} \mathrm{O}_{10}$ as determined from its high resolution (HR)-FAB-MS, ${ }^{13} \mathrm{C}$-NMR, and ${ }^{13} \mathrm{C}$-distortionless enhancement by polarization transfer (DEPT) spectral data. The UV spectrum of 1 showed absorption maxima at 273 and $346 \mathrm{~nm}$. These results suggest $\mathbf{1}$ is a flavone derivative. The ${ }^{1} \mathrm{H}-\mathrm{NMR}$ spectrum of 1 was characteristic of a chrysoeriol moiety. ${ }^{1)}$ Signals at $\delta 6.87(1 \mathrm{H}, \mathrm{s})$ and $\delta 6.52(1 \mathrm{H}, \mathrm{s})$ were attributed, respectively, to $\mathrm{H}-3$ and $\mathrm{H}-8$ through the HMQC and the HMBC spectrum (Fig. 1), and a singlet at $\delta 3.88(3 \mathrm{H}, \mathrm{s})$ was assigned to an aromatic methoxyl group at the $3^{\prime}$-position in the B-ring through the HMBC and NOE difference spectroscopy. Furthermore, ABX-type aromatic proton signals at

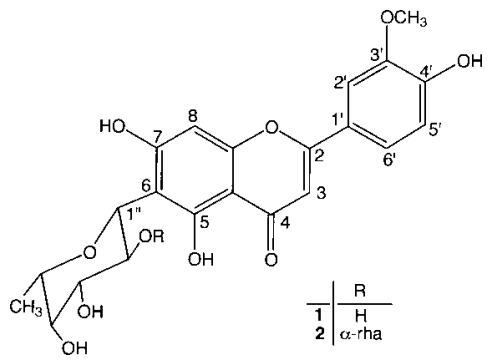

$\delta 7.55$ (s-like), $\delta 7.56$ (d-like, $J=2.1 \mathrm{~Hz}$, overlapped with signal at $\delta 7.55)$ and $\delta 6.92(\mathrm{~d}, J=9.2 \mathrm{~Hz})$ in B-ring were observed. These results including the appearance of a low-field signal at $\delta 13.45$ (brs) attributed to $\mathrm{OH}-5$ were compatible with chrysoeriol. The anomeric proton arising from the sugar moiety appeared at $\delta 4.62(\mathrm{~d}, J=9.8 \mathrm{~Hz})$, which correlated with a signal at $\delta 73.4$ in the HMQC spectrum. In the COSY spectrum (Fig. 1) the anomeric proton at $\delta 4.62$ was coupled to the proton at $\delta 4.01$, assigned to $\mathrm{H}-2^{\prime \prime}$. The observation of cross-peaks between H-2" and resonance at $\delta 3.39$ and between resonance at $\delta 3.39$ and $\delta 3.54$ permitted the assignment of H-3" and H-4", respectively. The HMBC and the HMQC experiments of $\mathbf{1}$ indicated connections between $\delta$ $1.13, \delta 3.65$ and $\delta 3.54$. According to the coupling constants of these protons and literature values, ${ }^{4)}$ the structure of this sugar was $\beta$-fucose. The chemical shift value of the anomeric carbon and $\mathrm{HMBC}$ from the anomeric proton and the hydroxyl group at $\mathrm{C}-5$ indicated that the anomeric carbon $(\delta$ 73.4) of $\beta$-fucose was connected to C-6 through a $C$-linkage. Consequently, compound 1 was determined to be chrysoeriol 6-C- $\beta$-fucopyranoside (1).

Compound 2 had the molecular formula $\mathrm{C}_{28} \mathrm{H}_{32} \mathrm{O}_{14}$ as determined from FAB-MS, ${ }^{13} \mathrm{C}$-NMR and ${ }^{13} \mathrm{C}$-DEPT spectral data. The UV spectrum of $\mathbf{2}$ showed absorption maxima at 273 and $346 \mathrm{~nm}$. The ${ }^{1} \mathrm{H}-\mathrm{NMR}$ spectrum of 2 was very similar to that of $\mathbf{1}$. The two anomeric protons appeared at $\delta$ $4.71(1 \mathrm{H}, \mathrm{d}, J=9.5 \mathrm{~Hz})$ and $\delta 5.00(1 \mathrm{H}$, s-like $)$, which correlated respectively with signals at $\delta 71.2$ and $\delta 100.5$ in the HMQC spectrum. The COSY spectrum (Fig. 2), spin-decoupling, and NOE experiments showed that these glycosyl residues were $\beta$-fucose and $\alpha$-rhamnose. These spectral data were consistent with literature values. ${ }^{5)}$ The configuration of rhamnose was determined by measurement of $J_{\mathrm{C} 1, \mathrm{H} 1}$ value

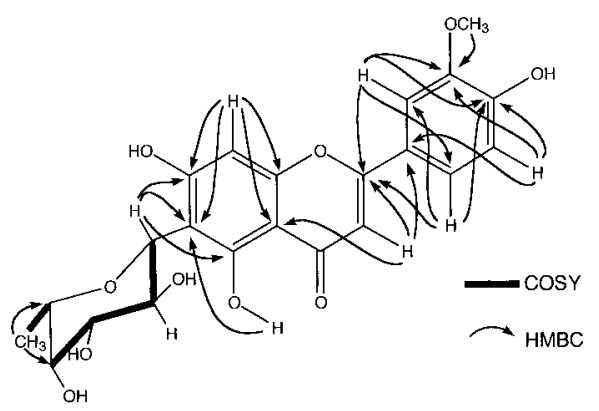

Fig. 1. HMBC and COSY of Compound $\mathbf{1}$ 


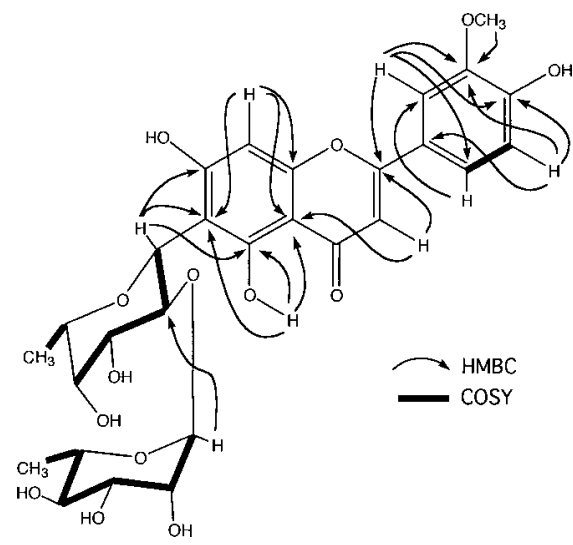

Fig. 2. HMBC and COSY of Compound 2

$(172.8 \mathrm{~Hz})$. The chemical shift values of these anomeric protons and the HMBC (Fig. 2) from these anomeric protons and the hydroxyl group at $\mathrm{C}-5$ indicated that the anomeric carbon ( $\delta 71.2$ ) of $\beta$-fucose was connected to C-6 through a $C$-linkage, and the anomeric carbon $(\delta 100.5)$ of $\alpha$-rhamnose was connected to C-2". Finally, it was concluded that $\mathbf{2}$ was ax-4"-OH-3'-methoxymaysin. The isolation of $\mathbf{2}$ was reported earlier by Snook E. M., et al. from this material, ${ }^{2}$ however, ${ }^{13} \mathrm{C}$ - and ${ }^{1} \mathrm{H}-\mathrm{NMR}$ chemical shifts of sugar residue were unassigned. Herein, we report the thorough assignment of the sugar moiety of $\mathbf{2}$.

Carrier protein in blood vessels, structural proteins, and enzymes in the body are modified by glucose in a process called glycation. It is known that accumulation of these glycated proteins (AGEs) causes diabetic complications. CML is the most characterized AGE and is referred to as a glycoxidation product. The inhibitory effects of compounds $\mathbf{1}$ and $\mathbf{2}$ on CML formation were tested by enzyme-linked immunosorbent assay (ELISA). Accumulation of CML in kidneys of diabetic subjects has been reported. ${ }^{3)}$ Inhibition was calculated to be $80.7 \%$ for $\mathbf{1}, 1.7 \%$ for 2 , and $61.3 \%$ for aminoguanidine at $1 \mathrm{~mm}$. Thus, $\mathbf{1}$ has an inhibitory effect on glycation with a percent inhibition value greater than that of aminoguanidine, a known glycation inhibitor.

\section{Experimental}

General Experimental Procedures Melting points were determined on a Yanako micro-melting point apparatus and were uncorrected. UV spectra and optical rotation were obtained with a Shimadzu UV 1600 spectrophotometer and a JASCO DIP-140 digital polarimeter, respectively. FAB-MS (positive ion mode, magic bullet matrix) were obtained with a JEOL JMS DX-302 mass spectrometer. ${ }^{1} \mathrm{H}$ - and ${ }^{13} \mathrm{C}$-NMR spectra were measured on a JEOL LA-500 spectrometer using tetramethylsilane as an internal standard. All chemical shifts $(\delta)$ are given in ppm, and the samples were solubilized in DMSO- $d_{6}$. HPLC was performed on a C-8 $(20 \mathrm{~mm}$ i.d. $\times 250 \mathrm{~mm}$, detector, UV $254 \mathrm{~nm})$ and a C-22 $(10 \mathrm{~mm}$ i.d. $\times 250 \mathrm{~mm}$, detector, UV $254 \mathrm{~nm})$ with aqueous $\mathrm{MeOH}$ as the mobile phase.

Plant Material The style of Zea mays L. (Gramineae) (Lot: COFQO15) was purchased from MIKUNI \& CO., LTD. (Osaka, Japan). A voucher specimen (No. NP 021011) was deposited with the laboratory of the Department of Natural Medicine and Phytochemistry at Meiji Pharmaceutical University.

Extraction and Isolation The dried style of Zea mays $(1 \mathrm{~kg})$ was extracted twice in $\mathrm{MeOH}(12 \mathrm{l})$ for $2 \mathrm{~h}$ at $50^{\circ} \mathrm{C}$, and the solvent was evaporated in vacuo to yield the $\mathrm{MeOH}$ extract $(13.4 \mathrm{~g})$. This extract was separated by chromatography on Diaion HP-20 $(50 \% \mathrm{MeOH} \rightarrow \mathrm{MeOH} \rightarrow$ acetone $)$ to yield the corresponding fractions. The $\mathrm{MeOH}$ fraction $(1.22 \mathrm{~g})$ was subjected to gel filtration chromatography (TOYOPAL HW-40F) using $\mathrm{MeOH}$ as solvent system. The effluents were combined into seven fractions based on TLC patterns. Fractions 5 and 4 were purified by reversed-phase (C-8, C-22) HPLC
Table 1. ${ }^{1} \mathrm{H}-\mathrm{NMR}$ Spectral Data of Compounds 1 and $2(500 \mathrm{MHz})$

\begin{tabular}{|c|c|c|}
\hline & 1 & 2 \\
\hline 3 & $6.87(\mathrm{~s})$ & $6.80(\mathrm{~s})$ \\
\hline 8 & $6.52(\mathrm{~s})$ & $6.46(\mathrm{~s})$ \\
\hline $2^{\prime}$ & 7.55 (s-like) & 7.53 (s-like) \\
\hline $5^{\prime}$ & $6.92(\mathrm{~d} 9.2)$ & $6.93(\mathrm{~d} 8.7)$ \\
\hline $6^{\prime}$ & 7.56 (d-like 2.1$)$ & 7.54 (d-like 1.8$)$ \\
\hline $\mathrm{OMe}$ & $3.88(\mathrm{~s})$ & $3.89(\mathrm{~s})$ \\
\hline $1^{\prime \prime}$ & $4.62(\mathrm{~d} 9.8)$ & $4.71(\mathrm{~d} 9.5)$ \\
\hline $2^{\prime \prime}$ & $4.01(\mathrm{t} 8.7)$ & $4.23(\mathrm{t} 9.3)$ \\
\hline $3^{\prime \prime}$ & $3.39(\mathrm{dd} 2.7,6.5)$ & $3.60(\mathrm{~m})$ \\
\hline $4^{\prime \prime}$ & $3.54(\mathrm{~d} 2.8)$ & $3.50(\mathrm{~d} 2.2)$ \\
\hline $5^{\prime \prime}$ & 3.65 (q 6.4) & 3.69 (q 6.1) \\
\hline $6^{\prime \prime}$ & $1.13(\mathrm{~d} 6.4)$ & $1.13(\mathrm{~d} 6.7)$ \\
\hline $1^{\prime \prime \prime}$ & & 5.00 (s-like) \\
\hline $2^{\prime \prime \prime}$ & & 3.63 (s-like) \\
\hline $3^{\prime \prime \prime}$ & & $3.23(\mathrm{dd} 2.9,9.2)$ \\
\hline $4^{\prime \prime \prime}$ & & $2.92(\mathrm{t} 9.5)$ \\
\hline $5^{\prime \prime \prime}$ & & $2.49 *$ \\
\hline $6^{\prime \prime \prime}$ & & $0.54(\mathrm{~d} 6.1)$ \\
\hline $5-\mathrm{OH}$ & $13.45(\mathrm{br} \mathrm{s})$ & 13.39 (br s) \\
\hline
\end{tabular}

Coupling constants $\left(J\right.$ in Hz) are given in parentheses. $\delta$ in DMSO- $d_{6}$ at room temperature. * Overlapped with signals of DMSO.

Table 2. ${ }^{13} \mathrm{C}-\mathrm{NMR}$ Spectral Data of Compounds 1 and 2 (125 MHz)

\begin{tabular}{lrr}
\hline \hline & 1 & $\mathbf{2}$ \\
\hline 2 & $163.4(\mathrm{~s})$ & $163.0(\mathrm{~s})$ \\
3 & $103.0(\mathrm{~d})$ & $102.9(\mathrm{~d})$ \\
4 & $181.8(\mathrm{~s})$ & $181.4(\mathrm{~s})$ \\
$4 \mathrm{a}$ & $103.1(\mathrm{~s})$ & $102.7(\mathrm{~s})$ \\
5 & $159.5(\mathrm{~s})$ & $159.1(\mathrm{~s})$ \\
6 & $109.3(\mathrm{~s})$ & $109.3(\mathrm{~s})$ \\
7 & $163.6(\mathrm{~s})$ & $164.5(\mathrm{~s})$ \\
8 & $94.4(\mathrm{~d})$ & $94.9(\mathrm{~d})$ \\
$8 \mathrm{a}$ & $156.3(\mathrm{~s})$ & $156.7(\mathrm{~s})$ \\
$1^{\prime}$ & $121.4(\mathrm{~s})$ & $121.2(\mathrm{~s})$ \\
$2^{\prime}$ & $110.2(\mathrm{~d})$ & $110.0(\mathrm{~d})$ \\
$3^{\prime}$ & $148.0(\mathrm{~s})$ & $148.1(\mathrm{~s})$ \\
$4^{\prime}$ & $150.8(\mathrm{~s})$ & $150.9(\mathrm{~s})$ \\
$5^{\prime}$ & $115.8(\mathrm{~d})$ & $115.8(\mathrm{~d})$ \\
$6^{\prime}$ & $120.3(\mathrm{~d})$ & $120.2(\mathrm{~d})$ \\
$1^{\prime \prime}$ & $73.4(\mathrm{~d})$ & $71.2(\mathrm{~d})$ \\
$2^{\prime \prime}$ & $68.6(\mathrm{~d})$ & $74.1(\mathrm{~d})$ \\
$3^{\prime \prime}$ & $75.0(\mathrm{~d})$ & $76.0(\mathrm{~d})$ \\
$4^{\prime \prime}$ & $71.6(\mathrm{~d})$ & $72.3(\mathrm{~d})$ \\
$5^{\prime \prime}$ & $73.9(\mathrm{~d})$ & $73.4(\mathrm{~d})$ \\
$6^{\prime \prime}$ & $17.0(\mathrm{q})$ & $17.0(\mathrm{q})$ \\
$1^{\prime \prime \prime}$ & & $100.5(\mathrm{~d})$ \\
$2^{\prime \prime \prime}$ & & $70.6(\mathrm{~d})$ \\
$3^{\prime \prime \prime}$ & & $70.4(\mathrm{~d})$ \\
$4^{\prime \prime \prime}$ & & $71.5(\mathrm{~d})$ \\
$5^{\prime \prime \prime}$ & & $68.1(\mathrm{~d})$ \\
$6^{\prime \prime \prime}$ & & $17.5(\mathrm{q})$ \\
& &
\end{tabular}

$\delta$ in DMSO- $d_{6}$ at room temperature.

eluting with a $\mathrm{MeOH}-\mathrm{H}_{2} \mathrm{O}$ mixture to afford $\mathbf{1}(3.8 \mathrm{mg})$ and $\mathbf{2}(6.1 \mathrm{mg})$, respectively.

Compound 1: Yellow amorphous solid, $\mathrm{mp} 195-198^{\circ} \mathrm{C},[\alpha]_{\mathrm{D}}^{25}+15.0^{\circ}$ $(c=0.32, \mathrm{MeOH})$. UV $\lambda_{\max }(\mathrm{MeOH}) \mathrm{nm}(\log \varepsilon): 273(4.23), 346(4.33) .{ }^{1} \mathrm{H}-$ and ${ }^{13} \mathrm{C}$-NMR: see Tables 1 and 2. HR-FAB-MS (positive) $\mathrm{m} / \mathrm{z}$ : 447.1302 $[\mathrm{M}+\mathrm{H}]^{+}$(Calcd for $\mathrm{C}_{22} \mathrm{H}_{23} \mathrm{O}_{10}: 447.1291$ ).

Compound 2: Yellow amorphous solid, mp $205-208^{\circ} \mathrm{C},[\alpha]_{\mathrm{D}}^{25}+19.4^{\circ}$ $(c=0.36, \mathrm{MeOH})$. UV $\lambda_{\max }(\mathrm{MeOH}) \mathrm{nm}(\log \varepsilon): 273(4.16), 346(4.26) .{ }^{1} \mathrm{H}-$ and ${ }^{13} \mathrm{C}$-NMR: see Tables 1 and 2. FAB-MS (positive) $m / z: 593[\mathrm{M}+\mathrm{H}]^{+}$. ${ }^{1} \mathrm{H}$ - and ${ }^{13} \mathrm{C}$-NMR: see Tables 1 and 2.

Inhibition Test on CML Formation in Vitro Bovine serum albumin 
(BSA) $(4 \mathrm{mg} / \mathrm{ml})$ was incubated with $100 \mathrm{~mm}$ glucose in the presence or absence of test compound for $7 \mathrm{~d}$ in $0.1 \mathrm{~m}$ phosphate buffer $\left(\mathrm{pH} \mathrm{7.4)}\right.$ at $37^{\circ} \mathrm{C}$. After incubation, the level of CML was measured by CML-specific ELISA based on the method described by Horiuchi. ${ }^{6}{ }^{6}$ The level of CML of each incubated mixture was the mean value of duplicate experiments. Inhibition was calculated as follows: inhibition $\%=\left[1-\left(A_{\mathrm{s}}-A_{\mathrm{b}}\right) /\left(A_{\mathrm{c}}-A_{\mathrm{b}}\right)\right] \times 100$, where $A_{\mathrm{s}}$ is the level of CML of the incubated mixture with sample, $A_{\mathrm{c}}$ is the level of CML of incubated mixture without sample as a positive control and $A_{\mathrm{b}}$ is the level of CML of incubated mixture without sample and glucose as a blank control.

Acknowledgements This work was supported in part by a grant for the promotion of advancement of education and research in graduate schools from the Ministry of Education, Culture, Sports, Science and Technology of
Japan. We thank for a grant from the Japan-China Medical Association.

\section{References}

1) Suzuki R., Okada Y., Okuyama T., J. Nat. Prod., 66, 564-565 (2003).

2) Snook E. M., Widstrom W. N., Wisem R. B., Byrne F. P., Harwood S. J., Costello E. C., J. Agric. Food Chem., 43, 2740-2745 (1995).

3) Singh R., Barden A., Mori T., Beilin L., Diabetologia, 44, 129-146 (2001).

4) Mareck U., Herrmann K., Galensa R., Wray V., Phytochemistry, 30, 3486-3487 (1991).

5) Zahid M., Ishrud O., Pan Y., Asim M., Riaz M., Ahmad U. V., Carbohydr. Res., 337, 403-407 (2002).

6) Horiuchi S., J. Biol. Chem., 226, $7329-7332$ (1992). 